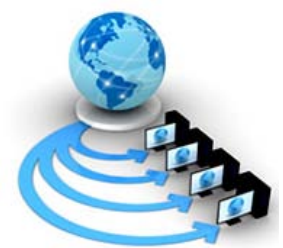

International Journal of Advanced Research in Computer Science

RESEARCH PAPER

\title{
LOCAL SEARCH BASED ALGORITHM FOR CVRP WITH STOCHASTIC DEMANDS
}

\author{
Harshdeep Kaur \\ Research Scholar \\ Department of Computer Engineering, \\ Punjabi University, Patiala, India
}

\author{
Mr. Harmandeep Singh \\ Assistant Professor \\ Punjabi University, Patiala, India
}

\begin{abstract}
This paper studies about the Capacitated vehicle routing problem (CVRP). Since the problem is NP-hard, a local search based algorithm is used for the CVRP with the target to limit the aggregate visited distance and number of vehicles. This algorithm is proven to be effective and as efficient for CVRP by checking its comparability with existing best known results. In this paper this algorithm is used for CVRPSD by increasing the demands the customers by $10 \%, 15 \%$, and $20 \%$ orderly. This algorithm is tested on the 5 problem set obtained from Augerat et. al CVRP benchmark problems which include instances range from 13 to 51 service nodes and number of homogeneous vehicles is changed from 2 to 8 according to problem set. The empirical outcomes demonstrate that this algorithm gives better arrangements than understood benchmark problems contrasted with those detailed in the literature.
\end{abstract}

Keywords: Capacitated Vehicle routing problem, Stochastic demands, Local Search, deviation

\section{INTRODUCTION}

The transportation problems assume a key part in the inventory network administration on the grounds that an item is once in a while delivered and absorbed in a similar place and furthermore decreasing the transportation cost prompts to improve the execution of organizations. The traditional Vehicle Routing Problem (VRP) comprises of deciding an arrangement of routes for indistinguishable vehicles to serve an arrangement of clients while limiting the aggregate cost of transportation. In the capacitated variation, signified by CVRP, just capacity limitations for vehicles are considered notwithstanding the essential components of the problem to such an extent that the request of every client, the distance between each match of client and the starting node(the warehouse). The normal goal is to lessen the aggregate cost (or length) of routes.

Throughout the years, a few solution strategies for the CVRP have been produced by analysts[1]. Xinyu Wanget.al[2]gives a novel ACO algorithm (called AMR) to clarify the VRP. The proposed algorithm empowers ants to go in and out the stops more than once until the point that they have gone to all customers, which revises the system of creating feasible routes of action. To moreover enhance AMR, they propose two extensions (AMR-SA and AMR-SA-II) by organizing AMR with other saving algorithms. This paper predominantly focuses on modifying the way toward creating achievable routes of action, yet not on improving the arrangement quality.Qianguo Chen et.al[3] formed SMPNACO algorithm by using the single inlet multi-outlet Physarum Network (SMPN) model's traits that key pipe focus on getting ready. The SMPNACO algorithm upgrades ant looking limit by strengthening the key pipeline pheromone concentration. The VRP Web informational collections are used to trial confirmation, found that the SMPNACO algorithm can satisfactorily handle the CVRP problem that in small scale, it can get extraordinary results and also has a higher quality. Regardless, when the information scale winds up recognizably greater, the SMPNACO algorithm preparing monotonous will increase, differentiated and standard ACS algorithm, which preferred standpoint will be incapacitated.

ACO method for solving the capacitated vehicle routing problem with stochastic demands was purposed by UdomJanjarassuket.al[4]. The outcomes when appeared differently in relation to the perfect costs from the deterministic varieties, all around the transportation cost increases $6: 57 \%$ when the demand deviation is $10 \%$, and increases 9:69\% when the demand deviation is $20 \%$.the future scope is by considering other stochastic parameters, for example, travelling time or the absence of clients and to enhance the nature of arrangements, where factual techniques could be connected for reliability examination by utilizing other metaheuristic strategies or neighbourhood change heuristics. Abel Garcia-Najera et.al[5] was proposed the use of as of late made meta-heuristic approach Similarity-based Selection Multi-objective Evolutionary approach (SSMOEA) for multi-target vehicle routing problems with backhauls (VRPB). The purposed algorithm contrasted and NSGA-II and MOEA/D alongside settled number of vehicles. IlkerKucukog et.al[6] gives hybrid meta heuristic algorithm in which enhanced nearest neighborhood search utilized for initial arrangements and $\Lambda$-interchange local search technique for neighborhood era to take care of Vehicle routing problem with backhauls with time windows.

In this paper, Local Search based algorithm is used for CVRP which gives optimal results in constant computational time. Further this algorithm is also used for CVRP with stochastic demands and calculate the deviation of cost and also calculate the deviation of capacity for that how much cost should be increased by it gives optimal results. The remaining of the paper is organized as follows. Section II provides a brief explanation of the capacitated vehicle routing problem including its stochastic variant. The Local Search algorithm for solving the CVRP is described in 
Section III. Computational results are given in Section IV, followed by a conclusion in Section V.

\section{CAPACITATED VEHICLE ROUTING PROBLEM DESCRIPTION}

The capacitated vehicle routing problem (CVRP) comprises of a single warehouse, a fleet of indistinguishable vehicles, and an arrangement of clients.[7] Every vehicle has a fixed capacity on the measure of products to be conveyed. The target of the problem is to discover possible routes to conveyance stock to every client with negligible cost. The vehicle routing problem can be considered as a network problem characterizing on a graph $\mathrm{G}=(\mathrm{N} ; \mathrm{A})$, where $\mathrm{N}$ is the set of nodes including warehouse, and $\mathrm{A}$ is the set of arcs associating the network.

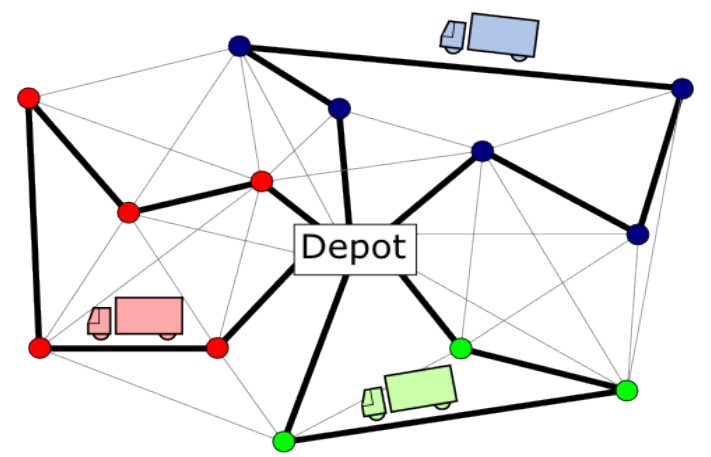

Figure1: Solution to capacitated vehicle routing problem

Moreover, the accompanying premises are considered in this investigation:

- $\quad$ Each vehicle must begin from the warehouse and come back to the warehouse.

- $\quad$ Each client must be served by a separate vehicle.

- The conveyance of the clients' requests is thought to be known from the factual information.

- If a client's request surpasses the rest of the limit of the arrival vehicle, the vehicle must come back to the warehouse to restock and keep on serving the unserved clients on the arranged.

In the capacitated vehicle routing problem with stochastic demands, the vehicle routes must be arranged early before knowing the correct demand of the customers.[4] After the vehicles arrive at the customer's the requests wind up a clearly made sense of it. The objective of the problem is to find the route of action of each vehicle's visits to such an extent, that the total expected cost is restricted. In case a client's demand outperforms whatever is left of the capacity of the arrival vehicle, the vehicle must return to the depot to restock and continue serving the unserved customers on the arranged route.

\section{MOTIVATION AND METHODOLOGY}

\section{1) Motivation}

In this paper, Local Search based optimization algorithm is used for CVRP to check its comparability with the existing best known results and results given by other algorithms. It is proven to be effective and as efficient algorithm for the problem of vehicle routing that is given in next section, which seems to be significant for CVRPSD.

To illustrate this, the demand of customers has been taken by increasing its $10 \%, 15 \%$, and $20 \%$ orderly. When the rise of demand is taken as $10 \%$ then it affects the travelled cost to reach the customers from the company which was more than the optimal distance because it is obvious that there is no such any customer which wants delay in product delivery. Moreover it also affects the cost of transportation as well as company loss. To tackle this problem the company has to find the solution to resolve this and it aims to increase the capacity of the vehicle, by which both the company as well as the customer can gain benefit. This is only reason due to which company increase the capacity of vehicle instead of adding a new vehicle or come back to depot for restock the vehicle.

\section{2) Methodology}

The purposed algorithm is based on local search algorithm for solving CVRP. For that firstly take the vehicles that are numbered between 1 to $\mathrm{K}$ and assigned the list of $\mathrm{N}$ visited customers to each vehicle. Then a constraint is applied which is for that each customer must visit only once. One vehicle $\mathrm{k}$ from total $\mathrm{K}$ vehicles assigned to route having $\mathrm{n}$ customers. By sum up the demands of each customer that are in one route and checked the capacity constraint with the capacity of the vehicle. Rest of customers is given to another vehicle. After all customers are assigned to vehicles then calculate the distance between each pair of adjacent vehicles by Euclidean distance. Then add up the distance from the depot to the first customer of route and from the last customer (n-1) to the depot to the customers of one route. Then local search applied on the routes for minimizing the sum of travelled distance.

\section{3) Algorithmic Approach for CVRP}

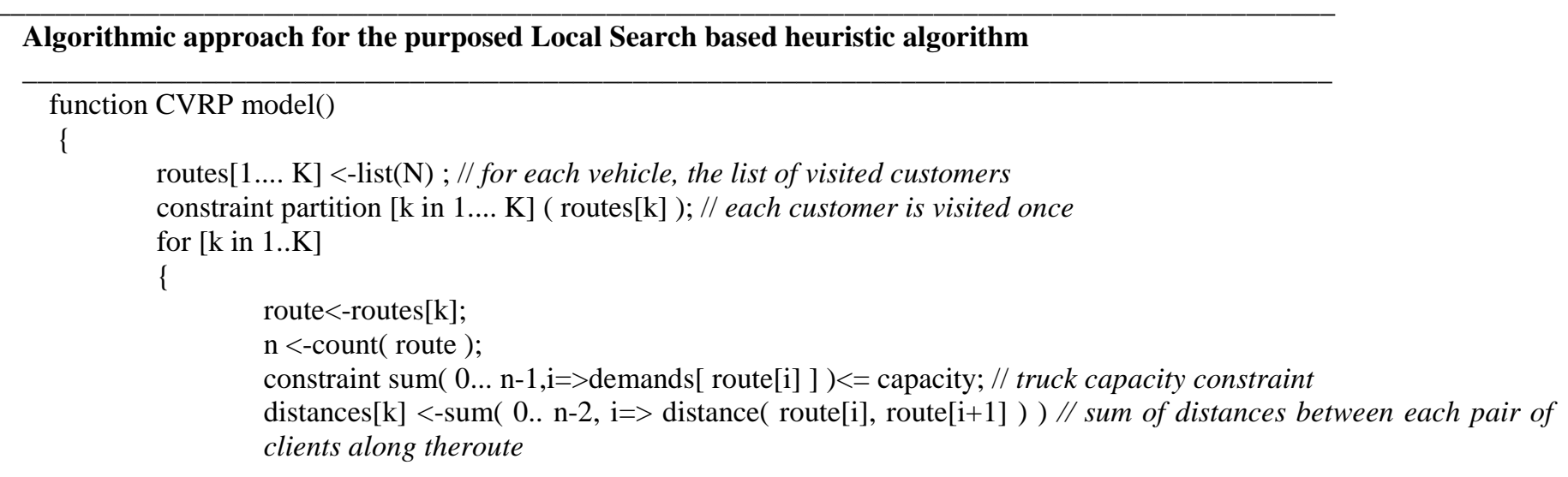


\}

+distance( depot, route[0] ) + distance( route[n-1], depot);

minimize sum[k in 1..K]( distances[k] ); // minimize sum of travelled distances \}

\section{COMPUTATIONAL RESULTS}

In this section, for demonstrate the effectiveness and applicability of this algorithm with best known results for CVRP with use of standard benchmarking data sets. This algorithm is implemented in Python programming language and executed on a computer equipped with AMD A8-7410 APU processor at $2.20 \mathrm{GHz}$ with an $8.00 \mathrm{~GB}$ RAM and an Ubuntu 16.04 LTS operating system. There is standard benchmark problem for the deterministic CVRP.

\section{A. Test Instances}

The benchmark data sets are derived from the following webpage

http://neo.lcc.uma.es/radiaeb/WebVRP/index.html?/Problem _Instances/instances.html of VRP instances. The testing problems are classified into five types in terms of the customer distribution and the demand distribution. Each type corresponds to a particular scenario for the customer distribution and the demand feature.The algorithm is tested for following five problem sets given in Table I.

TABLE I

BENCHMARK DATA SETS

\begin{tabular}{|c|c|c|c|c|}
\hline $\begin{array}{c}\text { N } \\
\text { o. }\end{array}$ & Problem & $\begin{array}{c}\text { No. of } \\
\text { Custome } \\
\text { rs }\end{array}$ & $\begin{array}{c}\text { No. of } \\
\text { vehicles }\end{array}$ & Capacity \\
\hline 1. & $\begin{array}{c}\text { P-n16- } \\
\text { k8 }\end{array}$ & 15 & 8 & 35 \\
\hline 2. & $\begin{array}{c}\text { P-n21- } \\
\text { k2 }\end{array}$ & 20 & 2 & 160 \\
\hline 3. & $\begin{array}{c}\text { B-n31- } \\
\text { k5 }\end{array}$ & 30 & 5 & 100 \\
\hline 4. & $\begin{array}{c}\text { A-n48- } \\
\text { k7 }\end{array}$ & 47 & 7 & 100 \\
\hline 5. & $\begin{array}{c}\text { B-n51- } \\
\text { k7 }\end{array}$ & 50 & 7 & 100 \\
\hline
\end{tabular}

\section{B. Evaluation metrics}

Algorithms are heuristic in nature; run the algorithms for many times and use the best result of data set as the obtained solution. To prove the effectiveness of purposed algorithm, compare the obtained solution with the best known solution. The travelling distance between two customers and between the customer and depot can be calculated by Euclidean distance. The total distance for different routes for vehicles is considered as a cost. The distance between two customers, customer $\mathrm{A}\left(\mathrm{x}_{1}, \mathrm{y}_{1}\right)$ and customer $\mathrm{B}\left(\mathrm{x}_{2}, \mathrm{y}_{2}\right)$ is calculated as follows:

$$
\text { Euclidean Distance }=\sqrt{\left(x_{2}-x_{1}\right)^{2}+\left(y_{2}-y_{1}\right)^{2}}
$$

The relative percentage deviation of the obtained best solution from the best known solution (RD1) for different methods is calculated as follows:

$$
\mathrm{RD} 1=\frac{\text { Obtained best solution }- \text { Best known solution }}{\text { Best known solution }}
$$

To evaluate the stability of each heuristic algorithm, the relative percentage deviation between solutions from all runs (RD2) is computed as follows:

$$
\mathrm{RD} 2=\frac{\text { Mean of all solutions }- \text { Obtained best solution }}{\text { Obtained best solution }}
$$

The indicator RD2 provides additional information about the stability of the algorithm. RD2 calculated for algorithms which are given in Table III.

The relative cost deviation while increase in demands of customers by $\mathrm{k} \%$ where $\mathrm{k}=10,15,20$ gives that the cost how much increase from optimal cost can be calculated as:

$$
\text { RD3 }=\frac{\text { change in cost }}{\text { optimal cost }}
$$

The relative capacity deviation while increase in demands of customers by $\mathrm{k} \%$ where $\mathrm{k}=10,15,20$ gives that by how much capacity of the vehicle can be increase from original capacity of vehicle that it gives the optimal cost can be calculated as:

$$
\mathrm{RD} 4=\frac{\text { change in capacity }}{\text { original capacity of vehicle }}
$$

C. Comparisons on Standard Benchmarks

The optimal costs from the original problems are also provided in the second column of the table. By using this algorithm it gives optimal results with in constant computational time i.e. $1 \mathrm{sec}$ for each problem but for some of the problems it takes more time. RD1 gives the relative percentage deviation that is calculated for these four algorithms and then reported in Table II. The negative sign indicates that purposed method gives the results that are lesser than best known results. The purposed method gives solution with RD1 $\leq-0.001$ while rest of that cannot perform well. 
TABLE II

RESULTS ON THE STANDARD DATA SETS WITH RELATIVE PERCENTAGE DEVIATION (RD1) FOR DIFFERENT METHODS

\begin{tabular}{|l|c|r|r|r|r|r|r|r|r|}
\hline \multirow{2}{*}{$\begin{array}{c}\text { N } \\
\mathbf{0}\end{array}$} & $\begin{array}{c}\text { Best } \\
\text { Known } \\
\text { results }\end{array}$ & \multicolumn{9}{|c|}{ Existing methods } & \multicolumn{2}{c|}{ Using Algorithm } \\
\cline { 3 - 10 } & & ARC & RD1 & $\begin{array}{c}\text { AMR- } \\
\text { SA }\end{array}$ & RD1 & $\begin{array}{c}\text { AMR-SA- } \\
\text { II }\end{array}$ & RD1 & $\begin{array}{c}\text { local } \\
\text { Search }\end{array}$ & RD1 \\
\hline $\mathbf{1 .}$ & 451.947 & 451.335 & - & 451.335 & - & 451.335 & - & 450 & - \\
& & & 0.001 & & 0.001 & & 0.001 & & 0.004 \\
\hline $\mathbf{2 .}$ & 212.712 & 212.712 & 0.000 & 212.712 & 0.000 & 219.093 & 0.030 & 211 & - \\
& & & & & & & & & 0.008 \\
\hline $\mathbf{3 .}$ & 676.758 & 677.448 & 0.001 & 677.448 & 0.001 & 708.071 & 0.046 & 672 & - \\
\hline $\mathbf{4 .}$ & 1074.338 & 1149.50 & 0.070 & 1148.85 & 0.069 & 1205.034 & 0.122 & 1073 & - \\
\hline $\mathbf{5 .}$ & 1035.71 & 1055.91 & 0.020 & 1055.47 & 0.019 & 1057.478 & 0.021 & 1032 & - \\
\hline
\end{tabular}

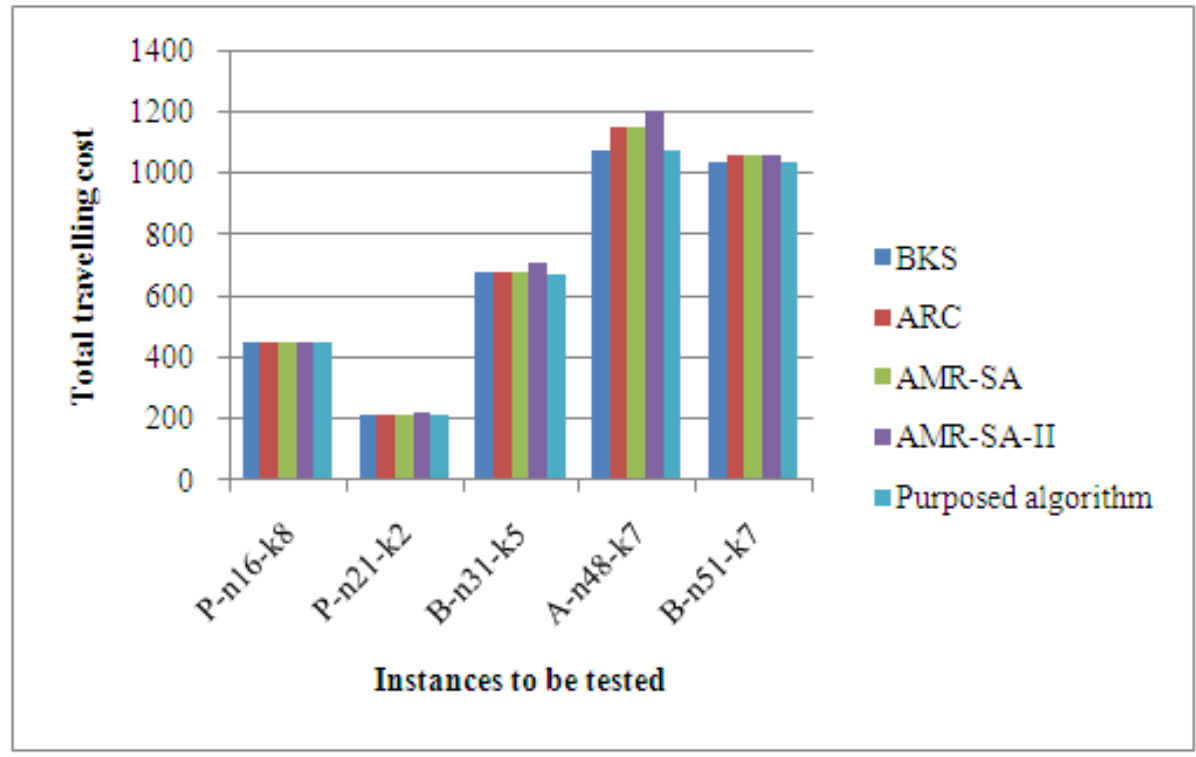

Figure 2 A graph showing the total travelling cost for the 4 algorithms compared with best known results

\section{Stability Comparisons}

As noted in table III, that analyze the stability regarding vehicle usage. Solutions are given by the use of same no. of vehicles. Our algorithm could always find optimal solutions in all runs for all cases in the constant computational time. This means that our algorithm is more stable than other algorithms.

TABLEIII

RESULTS ON THE STANDARD DATA SETS WITH RELATIVE PERCENTAGE DEVIATION (RD2) FOR DIFFERENT METHODS

\begin{tabular}{|c|c|c|c|c|}
\hline No. & ARC & $\begin{array}{c}\text { AMR- } \\
\text { SA-II }\end{array}$ & $\begin{array}{c}\text { AMR- } \\
\text { SA }\end{array}$ & $\begin{array}{c}\text { Purposed } \\
\text { Algorithm }\end{array}$ \\
\hline 1 & 0.000 & 0.000 & 0.000 & $\mathbf{0 . 0 0 3}$ \\
\hline 2 & 0.004 & 0.004 & -0.025 & $\mathbf{0 . 0 1 3}$ \\
\hline 3 & 0.007 & 0.007 & -0.036 & $\mathbf{0 . 0 1 5}$ \\
\hline 4 & -0.017 & -0.016 & -0.062 & $\mathbf{0 . 0 5 3}$ \\
\hline 5 & -0.008 & -0.008 & -0.010 & $\mathbf{0 . 0 1 5}$ \\
\hline $\begin{array}{l}\text { Ave } \\
\text { rage }\end{array}$ & $\mathbf{- 0 . 0 0 2}$ & $\mathbf{- 0 . 0 0 2}$ & $\mathbf{- 0 . 0 1 8}$ & $\mathbf{0 . 0 1 4}$ \\
\hline
\end{tabular}

E. Impact of Stochastic demands on cost and capacity

The table IV shows the results after taking the demand by increasing its $10 \%$. The cost and no. of vehicles are measured by using algorithm. The results are taken by increasing the capacity after getting the optimal cost. Further relative cost deviation is calculated which clarifies that how much cost is increased with the increase in demands of customers and relative capacity deviation is calculated which gives that how much capacity will be increased to get the optimal cost. Similarly table V and table VI shows the results after taking the demand by increasing its $15 \%$ and $20 \%$.

When the increase in demands by $10 \%$ then problem 1 i.e. P-n16-k8 having capacity 35 gives cost 472 with the use of 9 vehicles instead of 8 vehicles. Then have to change capacity of the vehicle. If the capacity increased to 39 from 35 then it takes 8 vehicles and also gets the optimal cost i.e. 450 . It means that for problem 1 cost increased by $4.9 \%$ if there is increase in demand by $10 \%$ and by rising the capacity of vehicle $10 \%$, it gives the optimal cost 450 with the use of 8 vehicles. 
TABLE IV

RESULTS ON THE STANDARD DATA SETS WITH RELATIVE COST (RD3) AND CAPACITY DEVIATION (RD4) FOR PURPOSED METHOD WHEN DEMAND INCREASED BY 10\%

\begin{tabular}{|c|c|c|c|c|c|c|c|c|}
\hline \multirow[t]{2}{*}{ No } & \multicolumn{3}{|c|}{$\begin{array}{l}\text { With increase in demands by } \\
\qquad 10 \%\end{array}$} & \multicolumn{3}{|c|}{$\begin{array}{l}\text { With increase in } \\
\text { capacity }\end{array}$} & \multirow{2}{*}{$\begin{array}{l}\text { Relative } \\
\text { cost } \\
\text { deviation } \\
\text { (RD3) }\end{array}$} & \multirow{2}{*}{$\begin{array}{c}\text { Relative } \\
\text { Capacity } \\
\text { deviation } \\
\text { (RD4) }\end{array}$} \\
\hline & Capacity & Cost & NV & Capacity & Cost & NV & & \\
\hline 1. & 35 & 472 & 9 & 39 & 450 & 8 & 0.049 & 0.103 \\
\hline 2. & 160 & 233 & 3 & 166 & 211 & 2 & 0.104 & 0.036 \\
\hline 3. & 100 & 690 & 5 & 107 & 672 & 5 & 0.027 & 0.065 \\
\hline 4. & 100 & 1180 & 7 & 114 & 1073 & 7 & 0.100 & 0.123 \\
\hline 5. & 100 & 1106 & 8 & 111 & 1032 & 7 & 0.072 & 0.099 \\
\hline \multicolumn{7}{|c|}{ Average deviation percentage } & 7.040 & 8.520 \\
\hline
\end{tabular}

TABLE V

RESULTS ON THE STANDARD DATA SETS WITH RELATIVE COST (RD3) AND CAPACITY DEVIATION (RD4) FOR PURPOSED METHOD WHEN DEMAND INCREASED BY 15\%

\begin{tabular}{|c|c|c|c|c|c|c|c|c|}
\hline \multirow[t]{2}{*}{ No } & \multicolumn{3}{|c|}{$\begin{array}{l}\text { With increase in demands by } \\
15 \%\end{array}$} & \multicolumn{3}{|c|}{$\begin{array}{l}\text { With increase in } \\
\text { capacity }\end{array}$} & \multirow{2}{*}{$\begin{array}{c}\text { Relative } \\
\text { Cost } \\
\text { deviation } \\
\text { (RD3) }\end{array}$} & \multirow{2}{*}{$\begin{array}{c}\text { Relative } \\
\text { Capacity } \\
\text { deviation } \\
\text { (RD4) }\end{array}$} \\
\hline & Capacity & Cost & NV & Capacity & Cost & NV & & \\
\hline 1. & 35 & 476 & 9 & 40 & 450 & 8 & 0.058 & 0.125 \\
\hline 2. & 160 & 236 & 3 & 175 & 211 & 2 & 0.118 & 0.086 \\
\hline 3. & 100 & 694 & 5 & 112 & 672 & 5 & 0.033 & 0.107 \\
\hline 4. & 100 & 1226 & 8 & 121 & 1050 & 7 & 0.168 & 0.174 \\
\hline 5. & 100 & 1184 & 9 & 116 & 1032 & 7 & 0.147 & 0.138 \\
\hline \multicolumn{7}{|c|}{ Average deviation percentage } & 10.480 & 12.600 \\
\hline
\end{tabular}

TABLEVI

RESULTS ON THE STANDARD DATA SETS WITH RELATIVE COST (RD3) AND CAPACITY DEVIATION (RD4) FOR PURPOSED METHOD WHEN DEMAND INCREASED BY 20\%

\begin{tabular}{|c|c|c|c|c|c|c|c|c|}
\hline \multirow{2}{*}{$\begin{array}{c}\text { No } \\
\text { • }\end{array}$} & \multicolumn{3}{|c|}{$\begin{array}{c}\text { with increase in demands by } \\
\mathbf{2 0}\end{array}$} & \multicolumn{2}{|c|}{$\begin{array}{c}\text { with increase in } \\
\text { capacity }\end{array}$} & \multirow{2}{*}{$\begin{array}{c}\text { Relative } \\
\text { Cost } \\
\text { deviation } \\
\text { (RD3) }\end{array}$} & $\begin{array}{c}\text { Relative } \\
\text { Capacity } \\
\text { deviation } \\
\text { (RD4) }\end{array}$ \\
\hline $\mathbf{1 .}$ & 35 & 476 & 9 & 43 & 450 & 8 & 0.058 & 0.186 \\
\hline $\mathbf{2 .}$ & 160 & 246 & 3 & 183 & 211 & 2 & 0.166 & 0.126 \\
\hline $\mathbf{3 .}$ & 100 & 717 & 5 & 120 & 672 & 5 & 0.067 & 0.167 \\
\hline $\mathbf{4 .}$ & 100 & 1223 & 8 & 125 & 1061 & 7 & 0.153 & 0.200 \\
\hline $\mathbf{5 .}$ & 100 & 1235 & 9 & 125 & 1014 & 7 & 0.218 & 0.200 \\
\hline \multicolumn{6}{|c|}{ Average deviation percentage } & & $\mathbf{1 3 . 2 4 0}$ & $\mathbf{1 7 . 5 8 0}$ \\
\hline
\end{tabular}




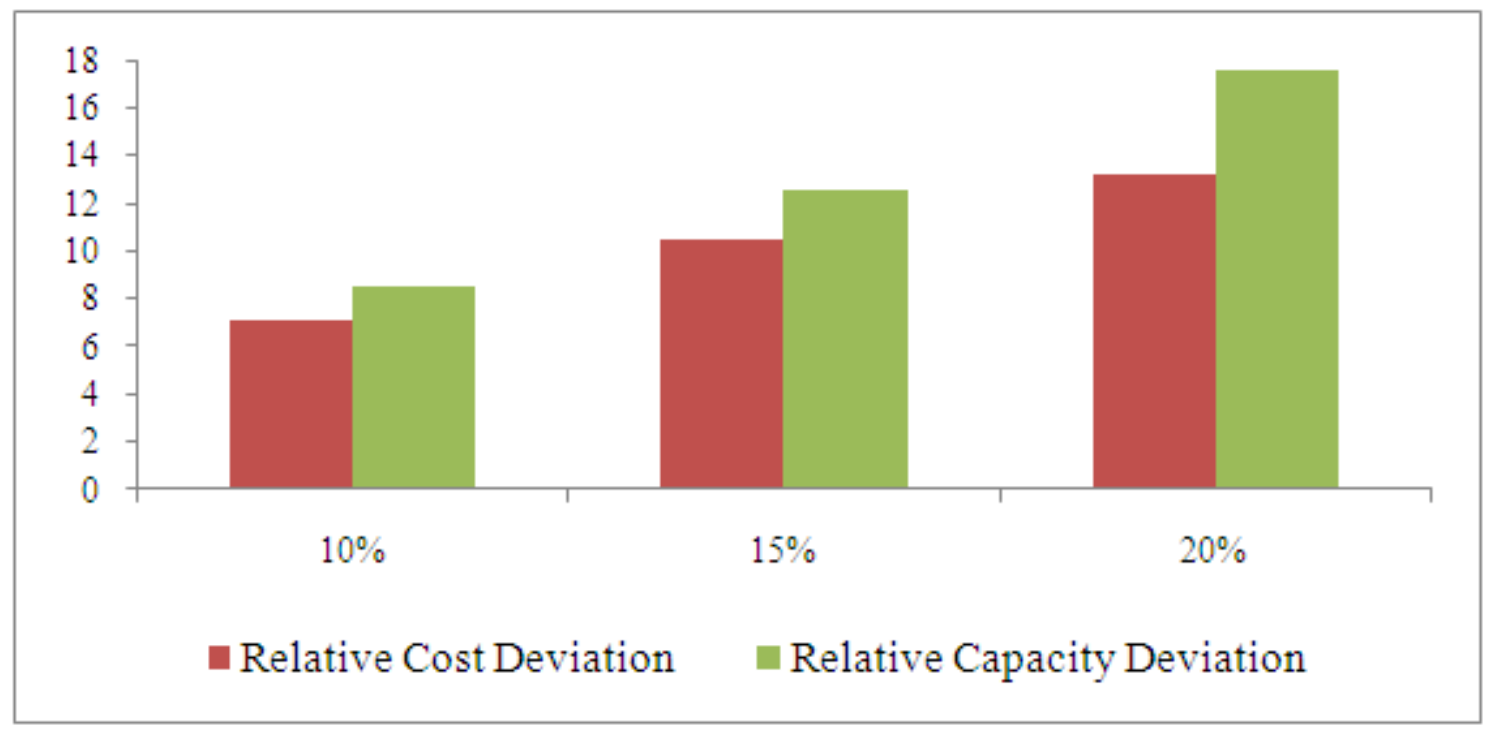

Figure 3 A graph showing the relative deviation of cost and capacity for the purposed algorithms compared with best known results when demand increased by $10 \%, 15 \%$, and $20 \%$ orderly

\section{CONCLUSION}

The purposed local search based algorithm is tested on a set of CVRP instances by generating customer demands from a uniform distribution. The results show that, when compared to the optimal costs from the deterministic variants, on average the transportation cost increases $7.04 \%$ when the demand deviation is $10 \%$, increases $10.48 \%$ when the demand deviation is $15 \%$ and increases $13.24 \%$ when the demand deviation is $20 \%$. To get the optimal cost have to increase the capacity of vehicles by $8.52 \%, 12.6 \%$, and $17.58 \%$ simultaneously. Future research work can be focused on CVRP variants using this algorithm and test the comparability with other algorithms.

\section{REFERENCES}

1. Harshdeep Kaur and Harmandeep Singh, "A Survey on Different Hybrid Meta Heuristics Algorithms for Vehicle Routing Problem," International Journal for Research in Applied Science \& Engineering Technology (IJRASET), vol. 5, no. VII, pp. 868-873, july 2017.

2. Xinyu Wang, Tsan-Ming Choi, Haikuo Liu, and Xiaohang Yue, "Novel Ant Colony Optimization Methods for Simplifying Solution Construction in Vehicle Routing
Problems," IEEE Transactions on Intelligent Transportation Systems, vol. 17, no. 11, pp. 3132--3141, 2016.

3. Qianguo Chen, Tao Qian, and Kui Liu, "A Logistic Distribution Routes Solving Strategy Based on the Physarum Network and Ant Colony Optimization Algorithm," in 2015 IEEE 17th International Conference on High Performance Computing and Communications (HPCC), 2015 IEEE 7th, 2015, pp. 1743-1748.

4. Udom Janjarassuk and Ruedee Masuchun, "An ant colony optimization method for the capacitated vehicle routing problem with stochastic demands," in Computer Science and Engineering Conference (ICSEC), 2016 International, 2016, pp. 1--5.

5. Abel Garcia-Najera and John Bullinaria, "An evolutionary approach for multi-objective vehicle routing problems," Computers $\backslash \&$ Industrial Engineering, vol. 81, pp. 90--108, 2015.

6. Marwa Amous, Said Toumi , Bassem Jarboui, and Mansour Eddaly, "A variable neighborhood search algorithm for the capacitated vehicle routing problem," Electronic Notes in Discrete Mathematics, vol. 58, pp. 231-238, 2017.

7. Chun-Chao Yeh, Da-Yuan Liu , and Yan-Kai Liao, "TwoStage Iterated Local Search for Solving capacitated vehicle routing problems," in Computer, Consumer and Control (IS3C), 2016 International Symposium on, 2016, pp. 45-48. 